\title{
A road map for seismic prevention of damage
}

\author{
M. Maugeri \& S. Grasso \\ Department of Civil and Environmental Engineering, Catania, Italy.
}

\begin{abstract}
The seismic prevention of damage is a challenge for the third millennium. In spite of the tremendous work on analytical and experimental studies to reduce seismic risk, many cities in the world are prone to seismic risk and the dead and loose are increasing exponentially in the past century.

The scientific, social and political awareness of Italian community leads the Italian Department of Civil Protection to funding the Research Project on earthquake damage scenarios for a high risk area in the Mediterranean. The area chosen was the mid-sized city of Catania, located in the Sicily island, situated in the central part of the Mediterranean area.

The road map for the evaluation of seismic prevention of damage follows the subsequent parts: the earthquake-source characterisation and seismic action evaluation at the bedrock for the scenario earthquakes (section 2); the site effects evaluation (section 3); the vulnerability analysis of physical environment for evaluating the risk related to cavities, landslides and liquefaction (section 4); the soil-structure interaction analysis for shallow foundation and retaining walls (section 5); the vulnerability analysis of monuments and r.c. buildings (section 6); the seismic structural improvement of r.c. buildings (section 7); vulnerability analysis of urban road and infrastructures (section 8).

The road map followed for the seismic prevention of damage could be considered a pilot project for detailed earthquake scenarios analyses and for seismic prevention of damage in many cities, characterised as the city of Catania by severe site amplification phenomena, landslides, liquefaction, presence of cavities, presence of many monuments and buildings not designed to resist against earthquakes. The seismic structural improvement of these buildings must be based on site dependent response spectra, evaluated from the characterisation of the earthquake source. The seismic structural improvement is needed for the sustainable development of many cities prone to seismic risk.

Keywords: earthquake source modelling, site effects and microzoning, environmental vulnerability, building vulnerability, seismic retrofitting of buildings
\end{abstract}




\section{Introduction}

The seismic prevention of damage is a multidisciplinary task involving a research team, made by geologists, geophysics, geotechnical, structural and transportation engineering and town planning. The road map followed for seismic prevention of damage could be considered as a guideline for the multidisciplinary task of assessment of the seismic hazard, the evaluation of the seismic risk, the prevention of seismic risk for new constructions and the mitigation of seismic risk in the existing constructions, including monuments and cultural heritage.

The road map for the evaluation of seismic prevention of damage follows the subsequent parts (Maugeri [1]): the earthquake-source characterisation and seismic action evaluation at the bedrock for the scenario earthquakes (section 2); the site effects evaluation (section 3); the vulnerability analysis of physical environment for evaluating the risk related to cavities, landslides and liquefaction (section 4); the soil-structure interaction analysis for shallow foundation and retaining walls (section 5); the vulnerability analysis of monuments and r.c. buildings (section 6); the seismic structural improvement of r.c. buildings (section 7); vulnerability analysis of urban road and infrastructures (section 8).

Section 2 is related to source characterisation and seismic action, which represents the biggest uncertainty in the overall process for design and retrofitting of buildings. In particular are discussed: the scenario earthquake given by the two destructive earthquakes of 1693, the modelling of the moderate earthquake of December 13, 1990 and the seismic response evaluation from micro-tremors and from numerical analyses.

Section 3 is related to site effects evaluation, which shows a great spatial variability in the urban area of Catania, due to the geological and geo-lithological features, as well as the non-linear behaviour of the soil; site effects have been evaluated in particular in some test areas and in the areas where cultural heritage are located.

Section 4 is related to vulnerability of physical environment, using Geographical Information Systems (GIS) technique. Among the vulnerability of physical environment related to potential landslides, potential liquefaction, presence of cavities etc., a response analysis of the Monte Po hill is presented, as well as the survey of the cavities, which are relevant for the city of Catania.

Section 5 is related to soil-structure interaction and to shallow foundation and retaining wall according to the suggestion of the Eurocode 8 Design of Structures for Earthquake Resistance.

Section 6 is related to the vulnerability analysis of buildings, by means of assessments and simulations using data from the Geographical Information System (GIS). An innovative approach is to link the vulnerability analysis to the seismic performance of RC buildings.

Section 7 is related to the seismic structural improvement of monuments and RC buildings. The Mediterranean cities are characterised by the presence of many monuments, which represent a world cultural heritage and must be preserved. Also the Mediterranean cities are characterised by buildings designed 
without any seismic provision, which must be improved to resist against earthquakes.

Section 8 is related to the early alarm and vulnerability of infrastructures systems and urban road. The heavy alarm can be given by the first Italian seafloor observatory, placed offshore the Catania coasts, connected by an underwater electro-optical cable to communicate with the surface communicator. The early alarm could be useful for many purposes as for the interruption of pipeline for gas distribution to avoid fire during and after earthquakes. Among the infrastructures, also the functionality analysis of the urban road network in seismic emergency are considered.

\section{Source characterisation and seismic action}

The seismic action is generally prescribed by probabilistic approach, considering the probability of exceeding a certain level during the life of the constructions. In Italy the probabilistic evaluation of the seismic action is based on the probability of exceeding of $10 \%$ of exceeding in 50 years, considering only the earthquakes with a return period less than 475 years. This criterion is not a conservative one, because generally speaking the life of the construction exceeds 50 years; in fact in many Italian medieval cities the buildings are standing from more than 500 years.

The Code of Federal Regulations (United States 1991) requires new municipal solid waste landfills to be designed either for a maximum horizontal acceleration taken from a published seismic map for a 10 percent probability of exceedance (90 percent probability of non exceedance) in a 250 -year exposure period or on the basis of a site specific analysis. The related return period for the map-based acceleration is 2375 years. The criterion of a site specific analysis is not specified in the regulation, but rather is left up to the individual states and may be probabilistic or deterministic. Because of the lower uncertainty, the return period for a site specific analysis may be less than 2375 years.

Increasing the historical knowledge of past earthquakes and changing the probabilistic criteria, the probabilistic approach leads to update the seismic action, which has been changed in the past in Italy (Fig. 1), so, buildings designed to resist to the given seismic action at the time of construction earthquakes could be not resisting at the updated seismic action.

Alternatively to the probabilistic approach, the road map for the evaluation of seismic damage takes into consideration the deterministic approach based on the evaluation of source mechanism. The scenario earthquake considered is the January 1693 events, as the biggest one; the February 1818 earthquake as medium earthquake and the December 1990 as a low earthquake (Fig. 2). The geological, geophysical and laboratory investigations performed provide additional constraints to the surface geological setting of the area as well as to the parameterization of the physical models. Numerical simulations have been applied with the twofold aim of estimating strong ground motion scenarios for different earthquake hypotheses and evaluating the effectiveness of 1-D nonlinear and 2-D and 3-D linear methods for the estimation of the local response. 


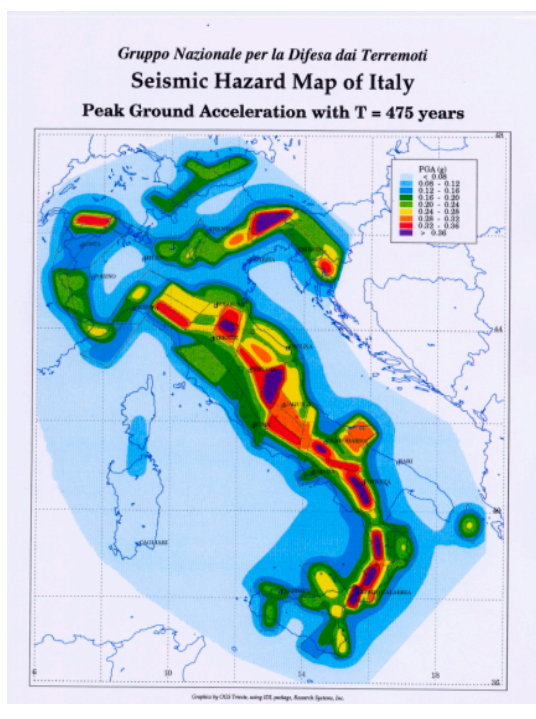

(a)

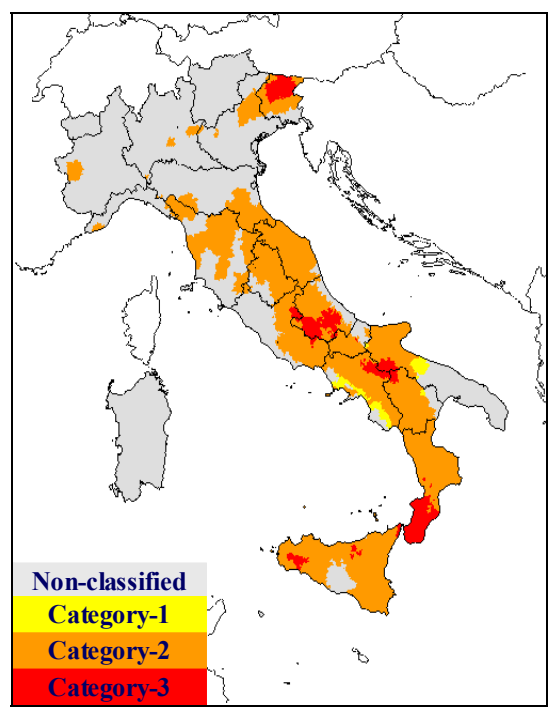

(c)

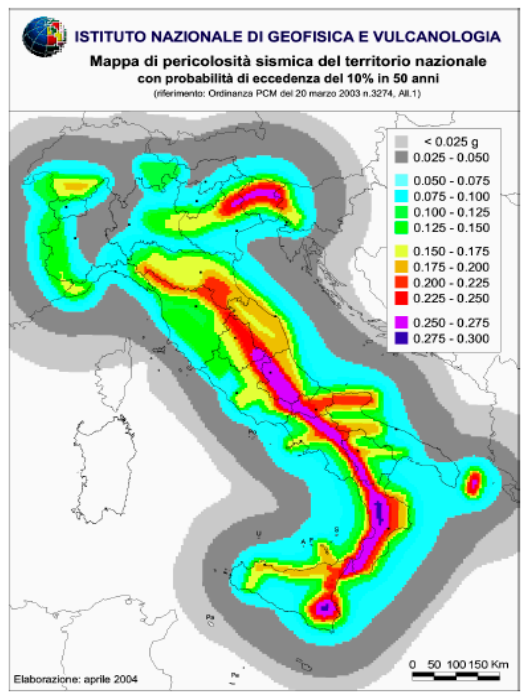

(b)

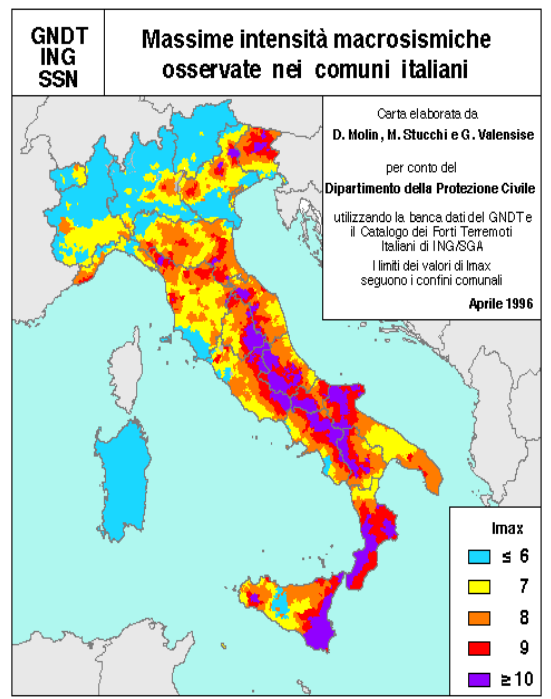

(d)

Figure 1: Seismic action: (a) Seismic hazard map of Italy in terms of acceleration proposed by the GNDT on 1984. (b) Seismic hazard map of Italy in terms of acceleration attached to the Ordinance O.P.C.M. 3274/2003 according to the Civil Defence of Italy. (c) National Seismic Regulation of Italy in terms of acceleration (category 2 for Catania area equal to $0.25 \mathrm{~g}$. (d) Maximum intensity felt in Italy (intensity $\supseteq 10$ for Catania area). 


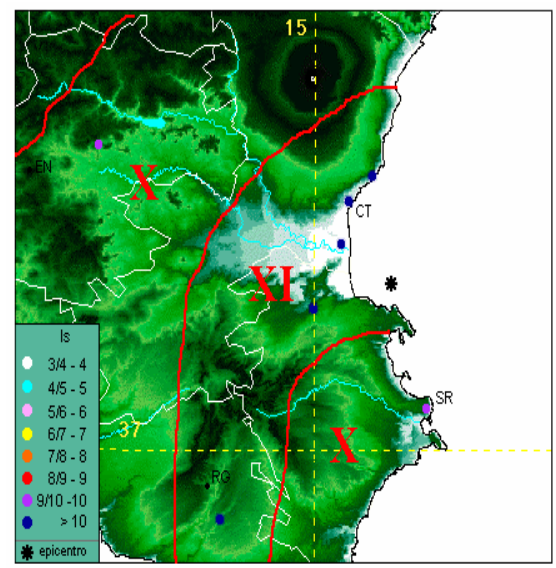

(a)

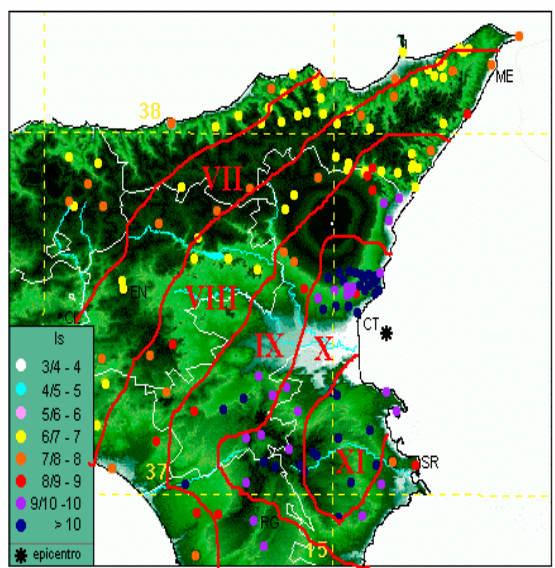

(b)

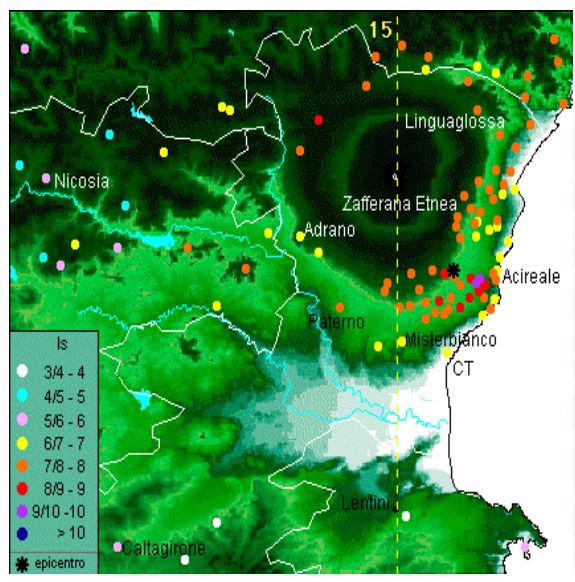

(c)

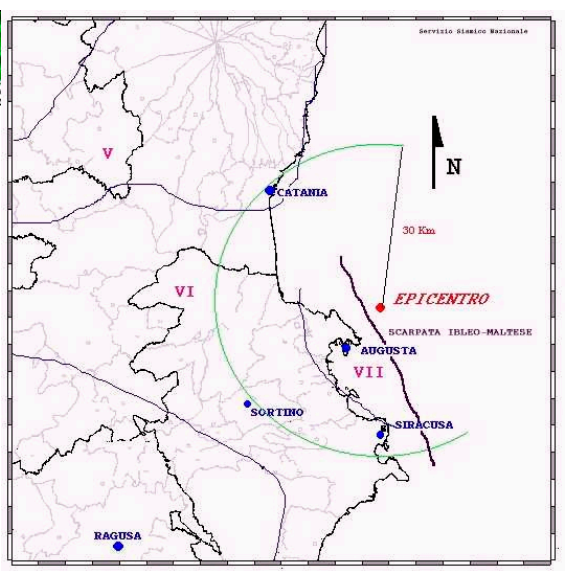

(d)

Figure 2: The scenario earthquakes: (a) Isoseismal map of the February 4, 1169 strong earthquake. (b) Isoseismal map of the January 11, 1693 scenario strong earthquake. (c) Map of the intensities of the February 20, 1818 scenario medium earthquake. (d) Isoseismal Map of the December 13, 1990 scenario low earthquake; the ground acceleration recorded at Catania $\left(2.43 \mathrm{~m} / \mathrm{s}^{2}\right)$ has amplitudes about 2,5 times larger than that recorded at Sortino $\left(1.003 \mathrm{~m} / \mathrm{s}^{2}\right)$, although both stations are at about the same epicentral distance (about $30 \mathrm{~km}$ ). 
The use of advanced methods capable of generating of synthetic seismograms can give a valuable insight into the evaluation of a seismic ground motion scenario.

The reference event is the catastrophic earthquake $(\mathrm{M} 7+)$ that struck Eastern Sicily on January 11, 1693, assumed as a level I scenario event in the Project.

The earthquake is linked to the Ibleo-Maltese fault system, which is the major seismogenic structure of Eastern Sicily.

The approach (Priolo [2] solves the 2-D full-wave propagation through laterally heterogeneous media, and therefore are well suited to provide accurate synthetic seismograms, and analyse the effect of the medium heterogeneity and local conditions on the ground motion. The approach uses a 2-D Chebyshev spectral element method. The ground motion is simulated along few selected transects (Fig. 3), where a realistic geological structure is defined, including the fine local details. A simplified extended source model is adopted. The results consist of detailed estimates of the main parameters that define the ground motion, and include some synthetic accelerograms at the surface and at a given depth (Fig. 4).

The reference medium earthquake is the February 20, $1818 \mathrm{M}=6.2$ earthquake, whose epicentre was close to the northern part of the present settlement of the city. Also this earthquake is considered a tectonic earthquake and is associated to the northern continuation of the Ibleo-Maltese fault system. Despite of its medium magnitude, the 'Catanese' earthquake has to be accounted for the seismic hazard assessment of Catania, because of its vicinity to the city.

The near-fault strong ground motion is computed through a hybrid stochasticdeterministic method (EXWIM). This method simulates rupture propagation along finite fault and solves the 3-D full-wave propagation in inelastic media with a vertically heterogeneous structure (Laurenzano et al. [3]). In order to evaluate an exhaustive scenario, different slip distributions and hypocenters are considered. The structural model assumed is representative of the Eastern Sicily area, however local site conditions are taken into account at each site in a simplified way (i.e. the $\mathrm{VS}_{30}$ value). The ground motion is computed for a regular grid of receivers sampling the urbanized area of Catania (Fig. 5).

The results consist of three-component waveforms, acceleration and displacement response spectra and other relevant parameters used to describe the ground motion (Fig. 6).

The seismicity of the Ibleo-Maltese escarpment is rather anomalous, since it generates a very low number of low to medium earthquakes. Consequently, there are only few events that can be used to validate numerical simulations of 1693 (strong) and 1818 (medium) earthquakes. The December 13, 1990, M = 5.8 earthquake is actually the only medium size event occurred along the northern segments of the Ibleo-Maltese system, which was recorded instrumentally. This earthquake is associated to a rupture of the transcurrent segment of the IbleoMaltese fault, and it was recorded by the ENEA-ENEL accelerometric network. Another reason of interest for modelling this earthquake is the fact that the seismogram recorded by the Catania ENEA-ENEL station shows anomalously large ground accelerations. 


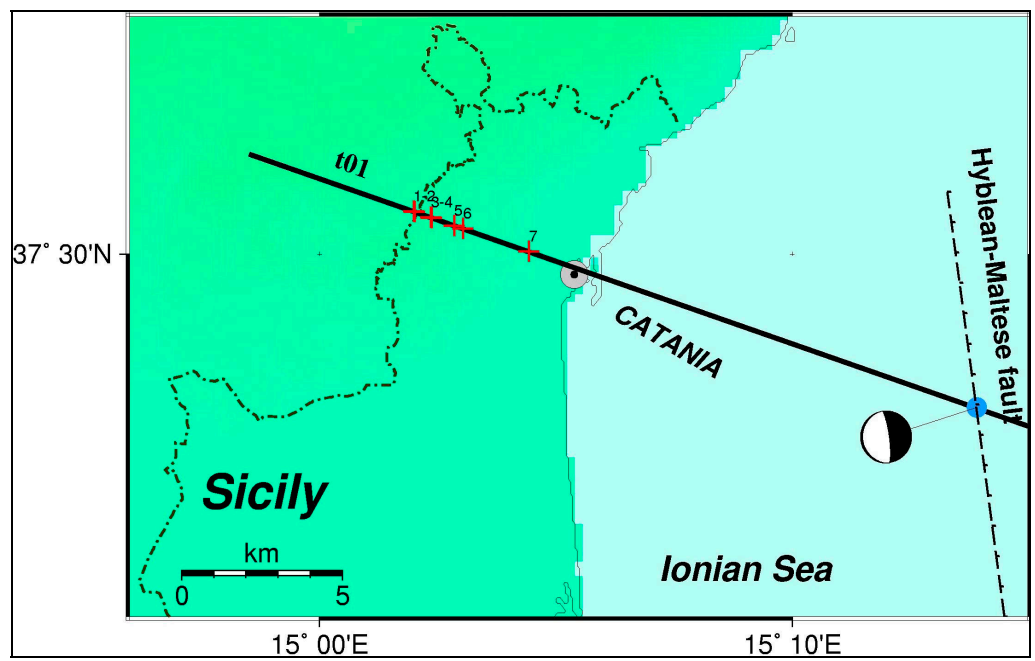

Figure 3: Base map of the study area, showing the transept position and the sites location. The blue circle shows the position assumed for the reference earthquake of January, 11, 1693.

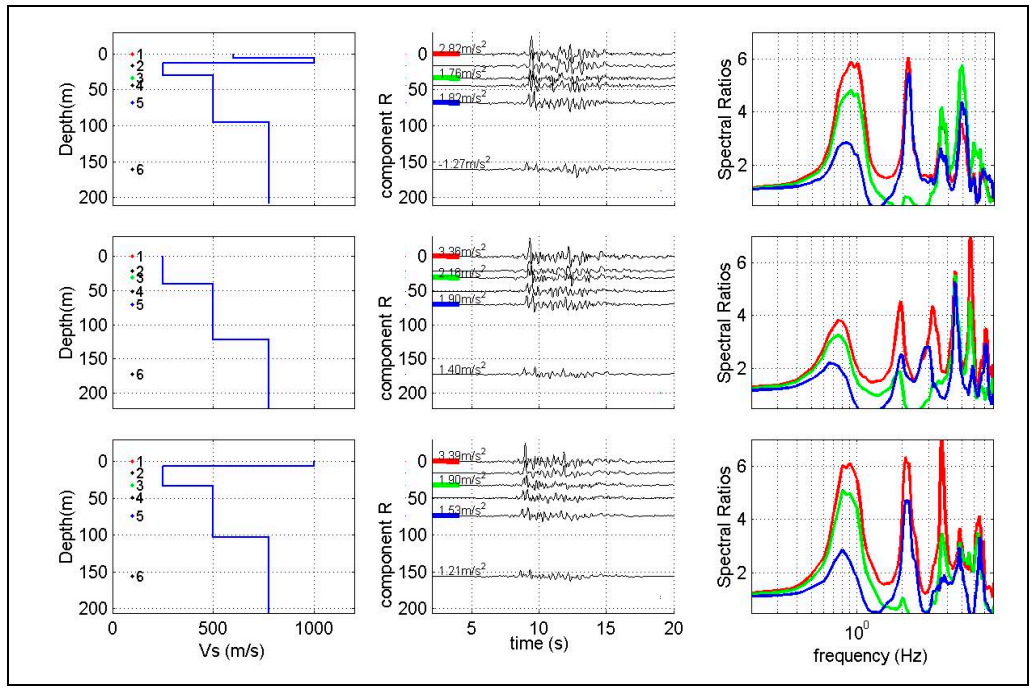

Figure 4: Site response at sites n. 1, 3, and 5 computed for a seismic moment distribution characterised by one dominant asperity. VS profile (left), acceleration time histories of the radial component (centre), and spectral ratios between the accelerations computed at different depths (i.e., receivers 1 (red colour, at ground surface), 3 (green, at $\mathrm{z} \gg 35 \mathrm{~m}$ ) and 5 (blue, at $\mathrm{z} \gg 70 \mathrm{~m}$ ), respectively) and receiver 6 , located within the bedrock at depth of about $170 \mathrm{~m}$. 


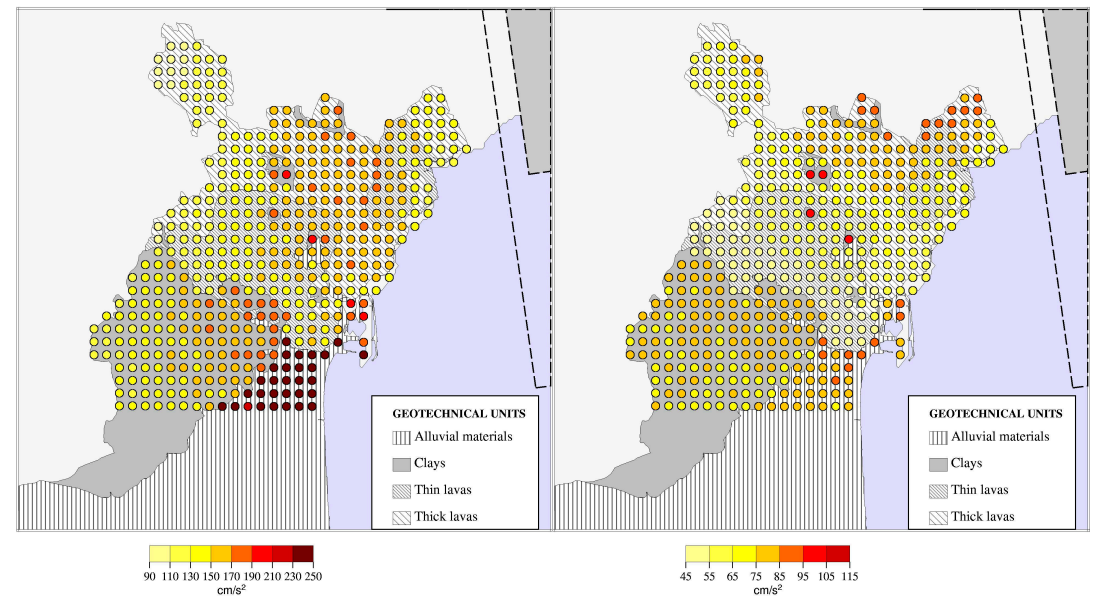

(a)

(b)

Figure 5: The average PGA scenario for 1818 earthquake, which consists of the mean value obtained considering the three fault sizes (small, medium and big), three slip distributions, two rake models (constant and variable) and all nucleation points, computed at each receiver. (a) Horizontal component; (b) vertical component (After Laurenzano et al. [3]).
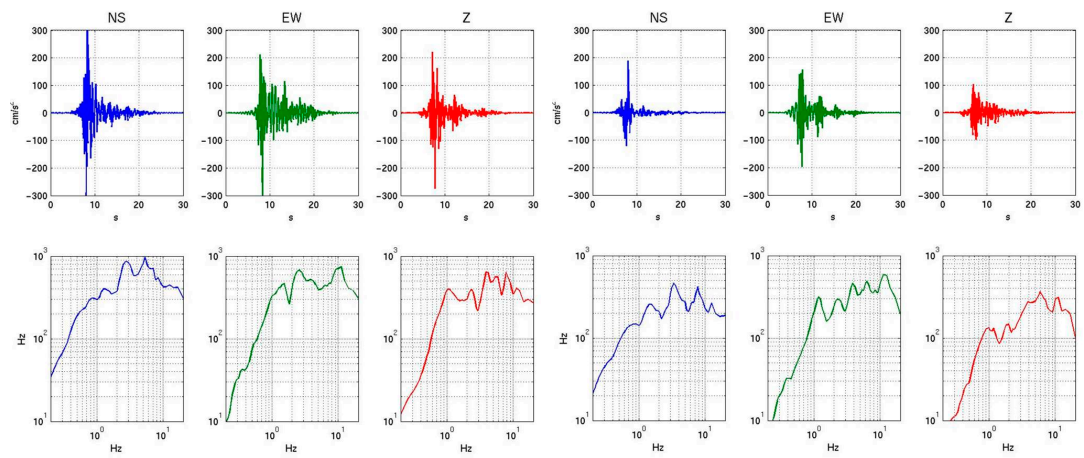

(a)

(b)

Figure 6: The seismograms and acceleration response spectra for medium size fault, variable rake distribution and up-dip rupture, computed at receivers located close each other for two different soil conditions. (a) fine alluvium of the plain; (b) lava (After Laurenzano et al. [3]). 
The ground acceleration recorded at Catania $\left(2.43 \mathrm{~m} / \mathrm{s}^{2}\right)$ has amplitudes about 2,5 times larger than that recorded at Sortino $\left(1.003 \mathrm{~m} / \mathrm{s}^{2}\right)$, although both stations are at about the same epicentral distance (about $30 \mathrm{~km}$ ) (see Fig. 2). These anomalies are attributed (e.g.: Di Bona et al. [4]) to both local site effects and the presence of strong crustal heterogeneities. The use of a method - the 2-D Chebyshev spectral element method - which solves the seismic full-wave propagation through a complex geological structure, is then of maximum interest to verify this kind of hypothesis (Laurenzano and Priolo [5]). In Fig. 7 it is possible to see the comparison between recorded and computed velocity and acceleration seismograms.

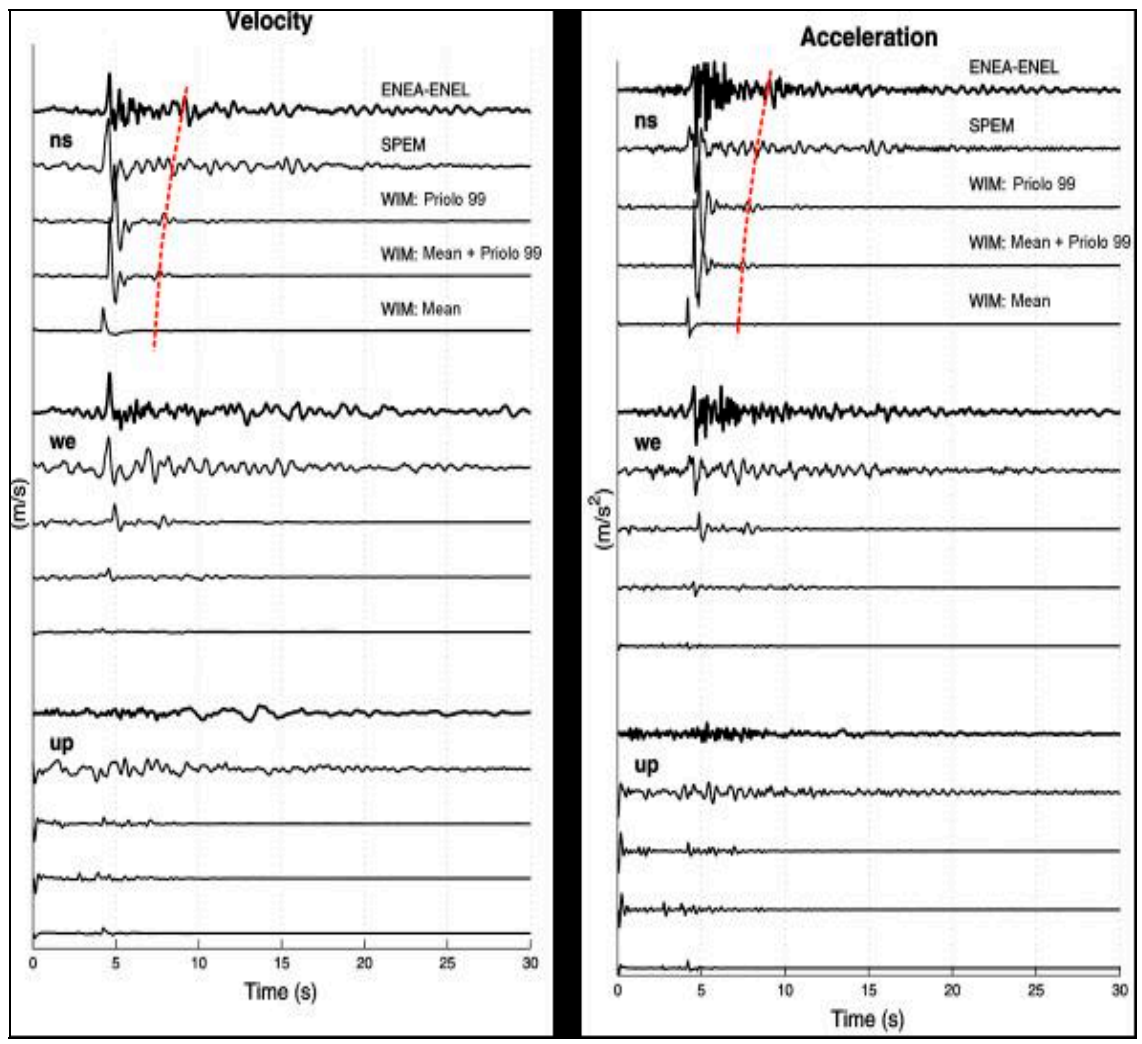

Figure 7. Three component velocity and acceleration seismograms recorded by the Catania ENEA-ENEL accelerometric station (thick lines) and computed numerically (thin lines) for different plane layer models. (WIM: Mean) mean regional structure; (WIM: Mean + Priolo [6]) deep structure of the mean regional model and shallow structure of the 2D model; (WIM: Priolo [6]) the best plane layer approximation of the 2D structure; (SPEM) 2D model (After Laurenzano and Priolo [5]). 


\section{Site effects and seismic microzoning}

Site effects evaluation for seismic microzoning is based on the geological model of the city of Catania and the geotechnical site characterisation including soil non linearity evaluation.

A detailed geological survey of part of the historical downtown has been carried out, therefore improving the previous geological map of Catania (Monaco et al., [7]). This study provides a more detailed mapping of the surface formations, and the results have been used to define the shallow layers of the ground motion simulation models, employed for the evaluation of site effects.

For geotechnical model a site characterisation empirical correlations between the shear waves velocity and geotechnical soil properties and direct in-situ measurements of shear waves velocity were made at specific test sites were used. Down-Hole (D-H), Cross Hole (C-H), Seismic Dilatometer Marchetti Test (SDMT) tests were performed at different test sites, geo-settled by GIS (Fig. 8). On the basis of empirical correlations and direct measurements of shear waves velocity, a geotechnical model is reported in Fig. 9.

For geotechnical characterisation static and dynamic laboratory tests were performed. The dynamic resonant column tests (RCT) and cyclic loading torsional shear tests (CLTST) were performed to detect soil non-linearity. In Fig. 10 are reported the shear modulus and damping ratio for the Plaja Beach test site for sandy soil (Cavallaro and Maugeri [10]). Similar evaluation has made also for clayey soil (Cavallaro et al. [11]).

The specific laboratory test for detecting soil non-linearity behaviour is a key point for evaluating local response and site effects, because as stated in paragraph 2.6, 1-D non-linear soil response is preferable to 2-D linear soil response in the flat epicenter area. The correct evaluation of local soil response is in turn a key point for the microzonation study reported in the following paragraph.

The site response of seven sites located in Catania has been evaluated through both 1-D and 2-D numerical simulations. The main goals of the study were: 1) to analyse how the wave-field is modified during its passage through the sequence of the shallowest soil layers of a 2-D model, 2) to compare the effect of different definitions of "bedrock seismic input" on 1-D simulations, and 3) to evaluate the range of applicability of non-linear 1-D and linear 2-D approaches (Laurenzano et al., [8] in the case of strong ground motion.

The 2-D spectral element method was used for the 2-D simulations. The investigated sites are located along transect $\mathrm{T}_{01}$ (Fig. 3). The shallow structure of the model has been defined in detail at the seven study sites using all the available geotechnical data. Seismograms have been computed (Fig. 4) at several depths, starting from the ground surface, in order to study the wave field propagation through about one hundred meter of surface soils.

The 1-D method, which is commonly used in engineering practice, takes into account the detailed shear waves soil profile of surface layers, including soil non-linearity. The seismic response at the ground surface has been evaluated 


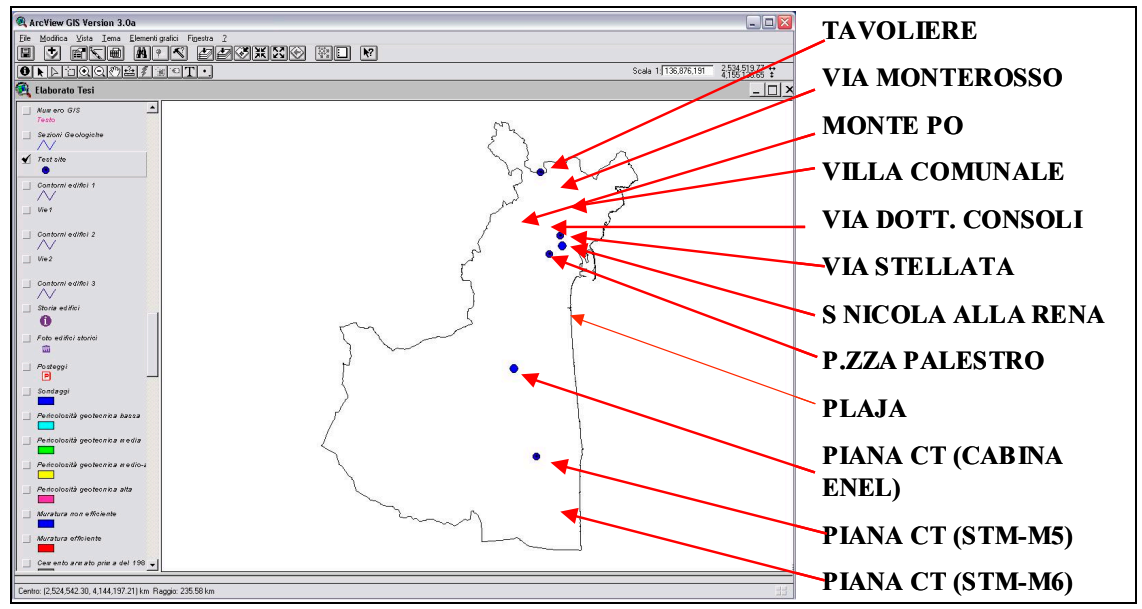

Figure 8: Test sites were direct measurements of Vs were performed: Cross-Hole test was performed at Piana CT (STM-M5); Down-Hole test was performed at Piana CT (STM-M5), Tavoliere, via Monterosso, via Dottor Consoli, via Stellata, San Nicola alla Rena, Piazza Palestro, Cabina ENEL; Seismic Marchetti Dilatometer Test (SDMT) was performed at Monte Po, Villa Comunale, Plaja, Piana CT-STM-M6.

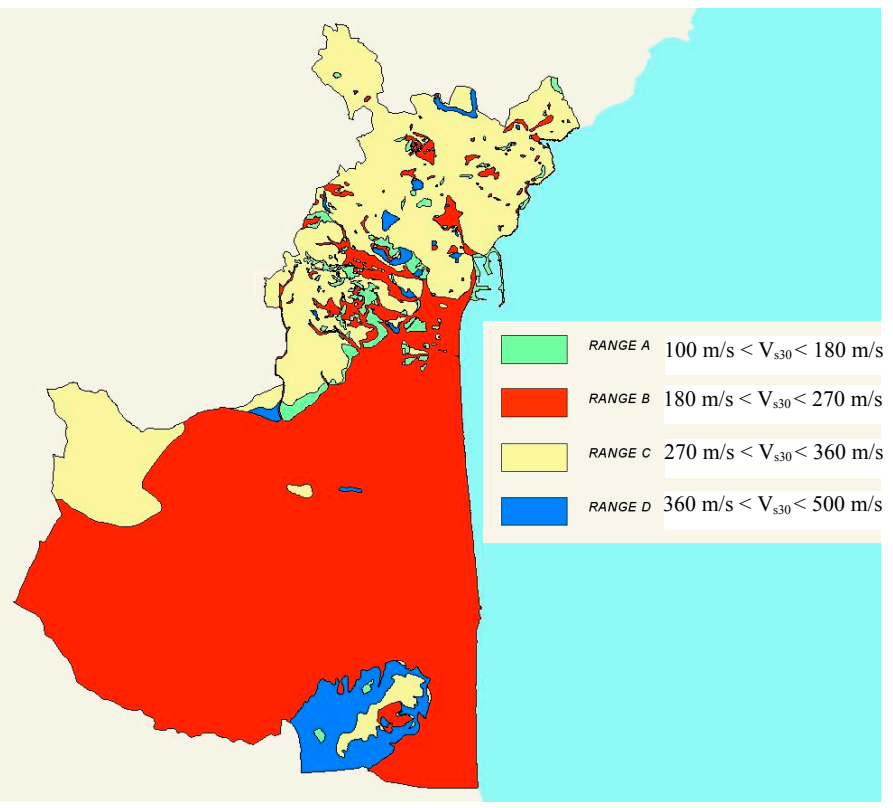

Figure 9: Geophysical map of the city of Catania based on shear waves velocity empirical correlations and measurements at the test sites. 


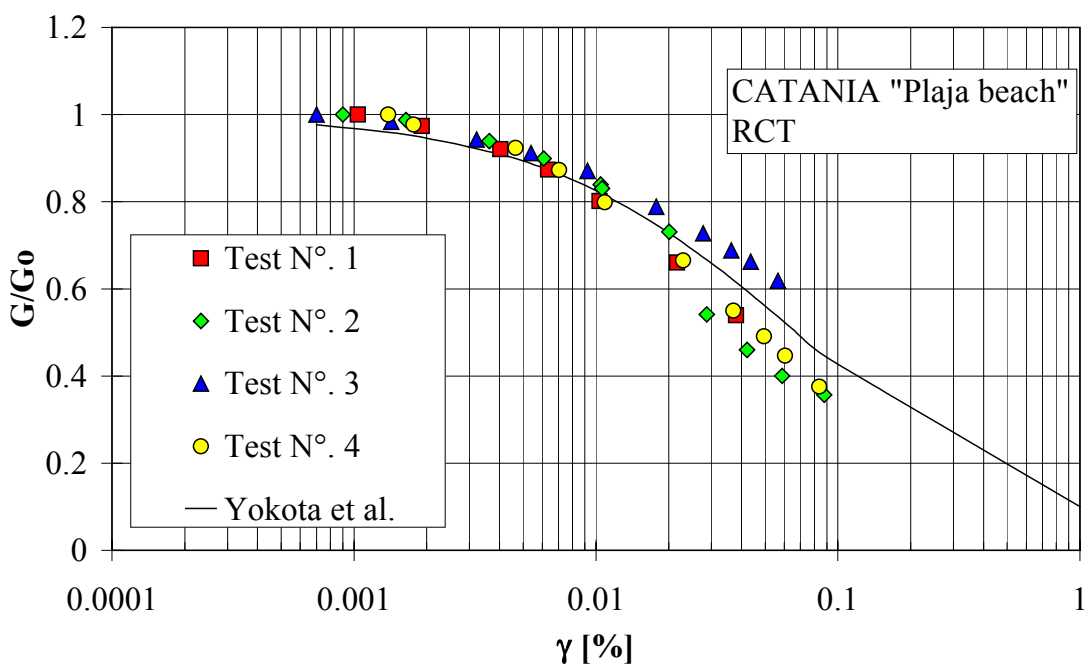

a) $\mathrm{G} / \mathrm{G}_{0}-\gamma$ curves from RCT for "Plaja beach" site.

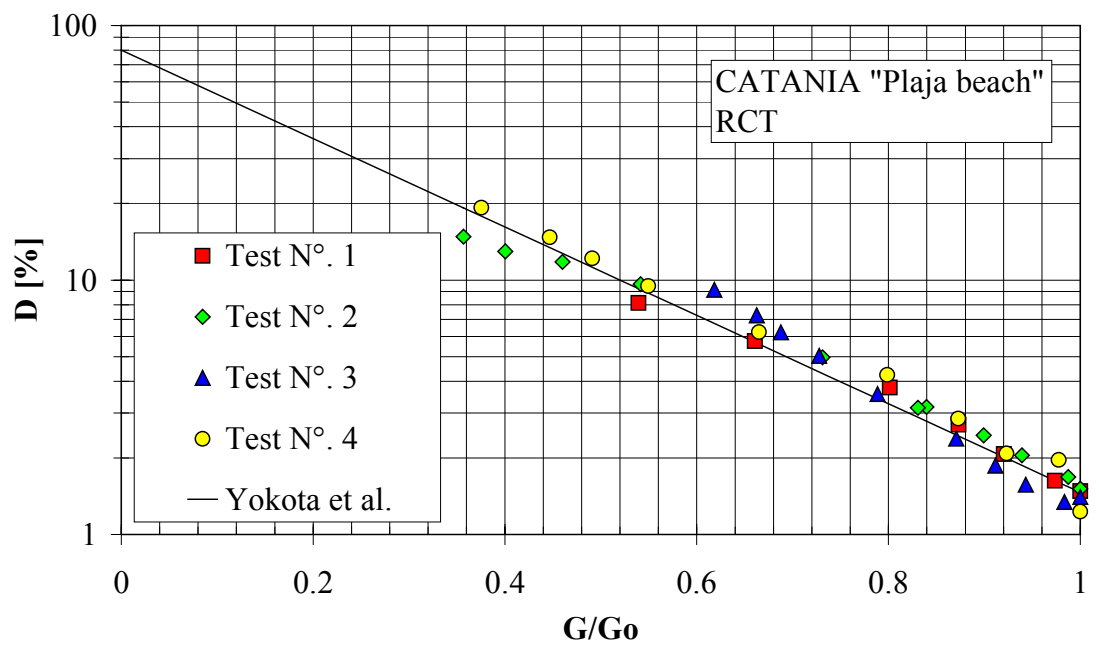

b) $\mathrm{D}-\mathrm{G} / \mathrm{G}_{0}$ curves from RCT for "Plaja beach" site

Figure 10: Soil non linearity for site response analysis (after Cavallaro and Maugeri [10]). 
defining the input motion through both a conventional approach (i.e., scaled recorded accelerograms at bedrock) and the synthetic accelerograms given by the 2-D code at a given depth (see section 2). The results show that the seismic input provided by the deterministic 2-D simulations, which reaches the value of about $0.5 \mathrm{~g}$, is considerably larger than the probabilistic one, and it has the effect of producing large non-linear behaviour within the soil column. Hence, 1-D nonlinear modelling has to be preferred to the 2-D linear one in the epicentre area, henever the soil structure can be approximated by a 1-D model.

The geophysical map of shear waves velocity was geo-settled, as well as the 1100 borings considered and the related soil profiles on which the 1-D site response were performed.

According to the Manual for Zonation on Seismic Geotechnical Hazards (ISSMGE [9]), the Grade 3 microzonation for ground movement of the city of Catania was performed. The geo-settled map of the microzonation of the whole city of Catania is reported in Fig. 11. The map shows the variability of peak ground acceleration due to the soil heterogeneity. It is also to be stressed that the expected peak ground acceleration evaluated by the deterministic approach and local site response given by the map is greater than that reported in Fig. 1a, based on probabilistic approach.

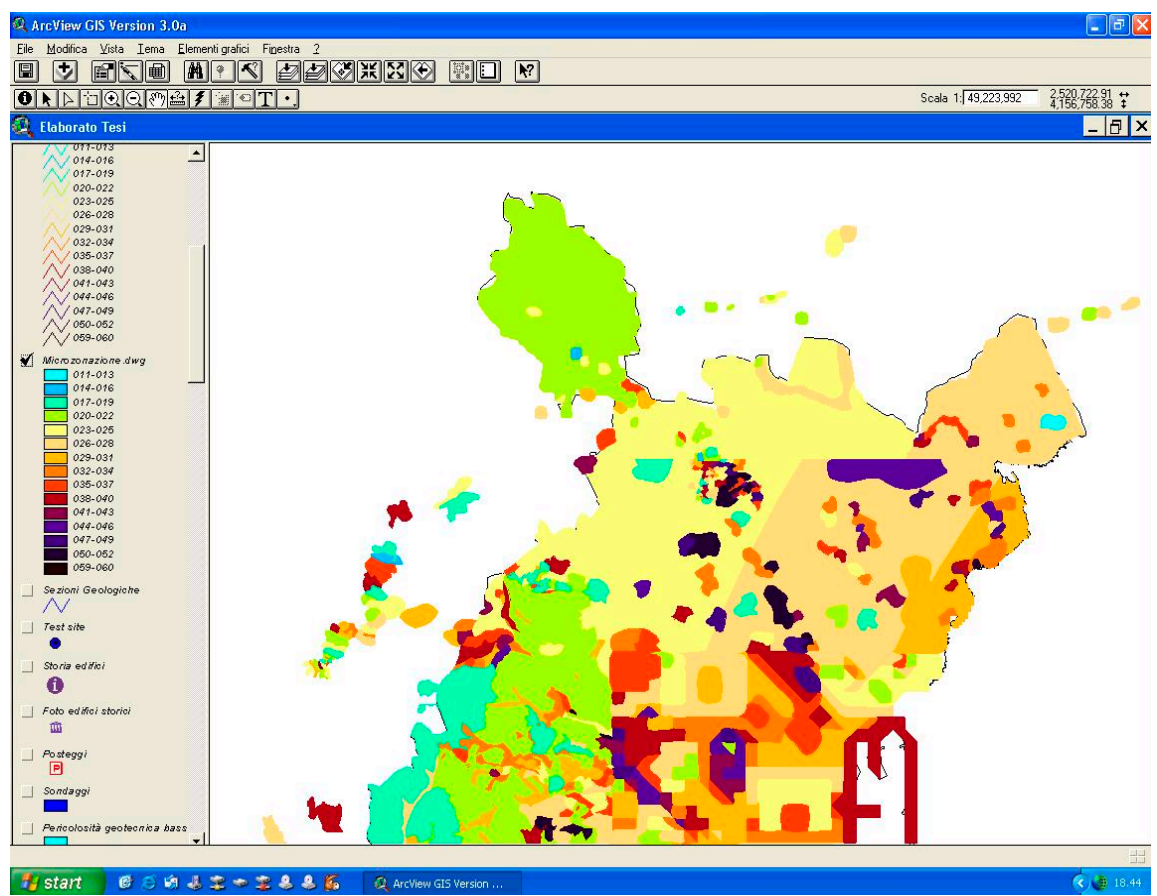

Figure 11: The geo-settled microzoning map in terms of peak ground acceleration based on deterministic evaluation for the January 11, 1693 strong scenario earthquake. 


\section{Vulnerability of seismic environment by landslides, liquefaction and cavity collapse}

Seismic vulnerability is generally linked with the analysis of vulnerability of building, while it is also very important to analyze the stability of soils where the buildings are founded. This new concept leads to the analysis of the vulnerability of physical environment.

The main goals for the vulnerability of physical environment are: modeling of the vulnerability of slopes to the Scenario Earthquake and application of the model one representative landslides behaviour, i.e. the Monte Po landslide, located in the urban area of Catania; modeling of liquefaction including instability due to lateral spreading; survey of the cavities under the Catania area and implementation of a database of detected cavities.

To detect the slope stability hazard two new models have been developed of which one for clay slope for which soil stability is affected by strength cyclic degradation (Biondi and Maugeri [12]) and one for saturated sand slope for which soil stability is affected by pore pressure build-up (Biondi et al. [13]). The model referred to clay slope has been applied for based displacement analysis of the Monte Po landslide in Catania (Figs. 12 and 13).

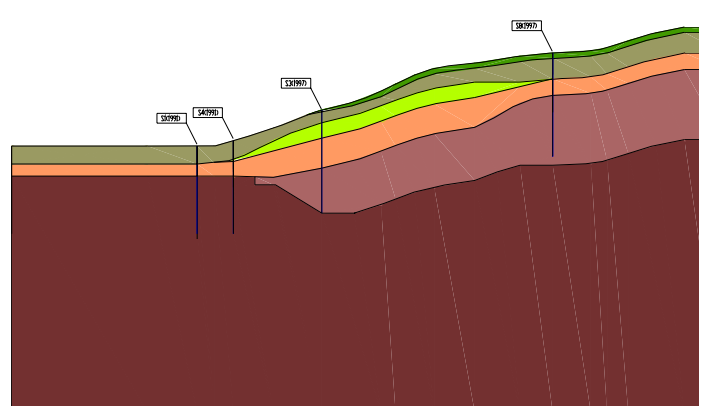

(a)

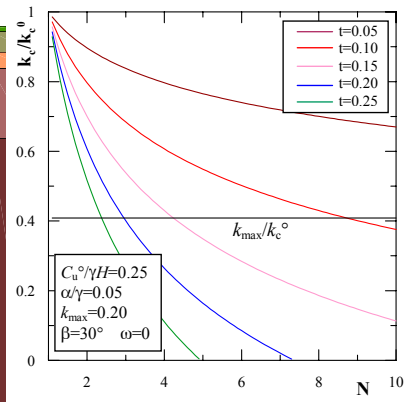

(b)

Figure 12: a) Schematic section of the Monte Po slope assumed in the analysis; b) Reduction of slope critical acceleration caused by the soil cyclic degradation.

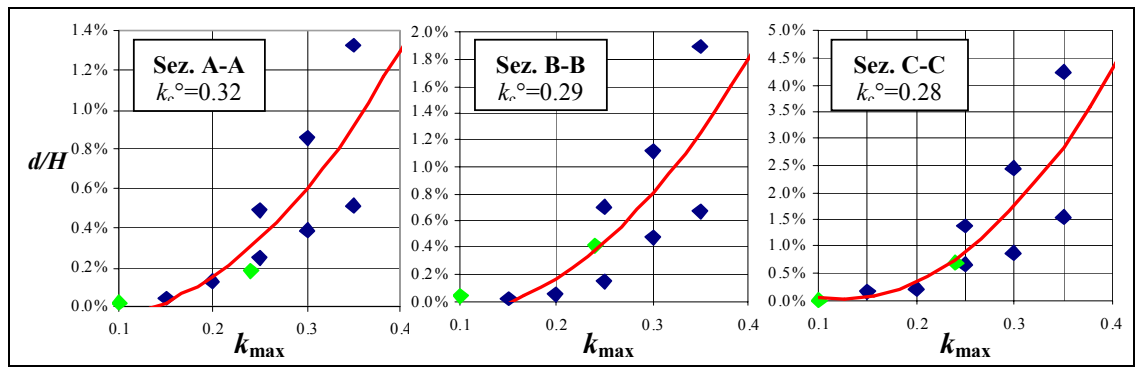

Figure 13: Results of the displacement response analysis of the Monte Po slope. 
The new model has been applied to the potential landslides in the city of Catania; the geo-settled microzoning map of landslides hazard is reported in Fig. 14.

The main landslide hazard is linked with the Monte Po landslide (No. 4 in the map), for which the stabilization work has been made. At high risk are also the Santa Sofia landslides (No. 2a and No. 2b), for which the stability analyses have been made. At medium risk level is the Acquicella landslide (No. 6), for which the stability analysis has been made. At low risk can be classified all the remaining landslides.

The model referred to the saturated sand slope has been applied to the shore line of Catania city were flow failure with lateral spreading can be expected because of liquefaction phenomena. The analysis of potential liquefaction (Grasso and Maugeri [14]) and of the lateral spreading leads to the geo-settled microzoning map of the liquefaction hazard (Fig. 15). All the Shore-line, along Catania beach, has been classified at high hazard, including part of the Harbor. At low hazard is the area near Librino and Pigno.

Survey of the cavities under the Catania area and implementation of a database of detected cavities have been made. The following cavities have been studied in detail: Casa di Sant'Agata, cavity Piazza A. Di Benedetto, cavities via Lavandaie, Pozzo Gammazita, cavity Piazza Currò, Cripta of S. Agostino Church (Bonaccorso et al. [15]). In the city of Catania the cavities represent a high risk for foundation stability of some buildings (Fig. 16).

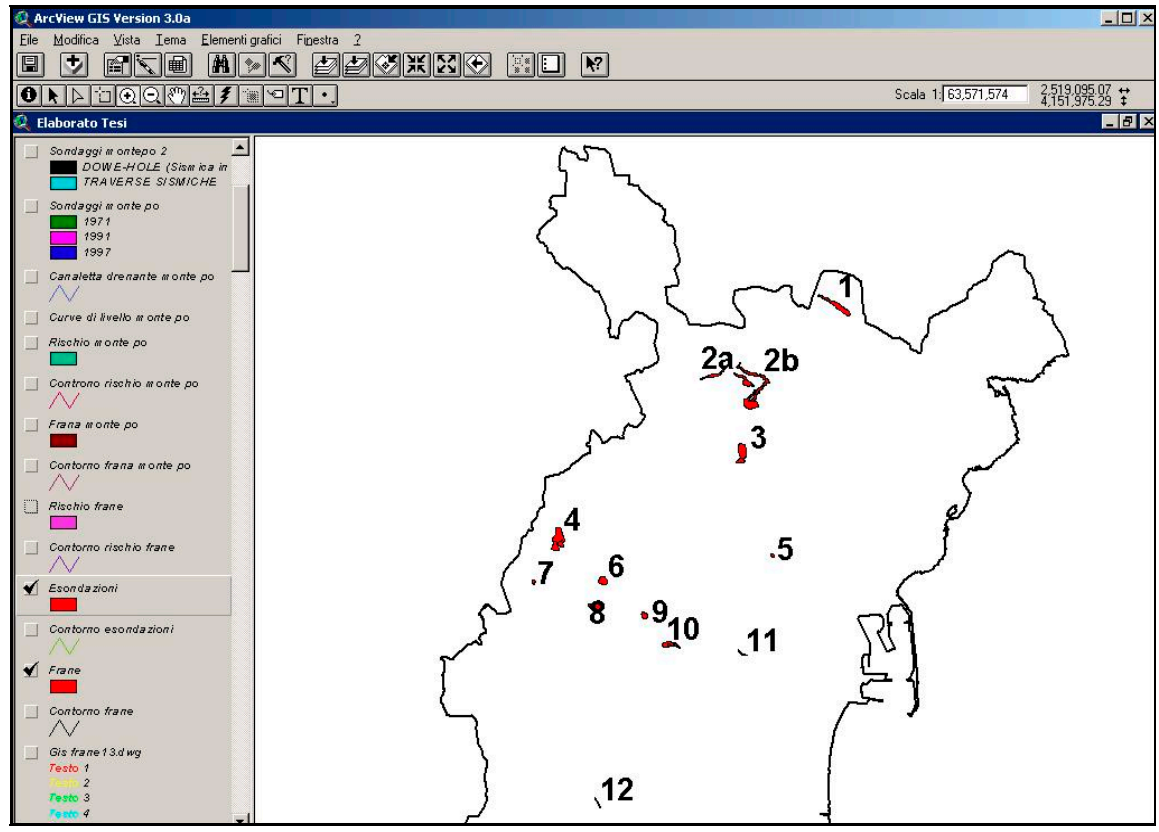

Figure 14: GIS localisation of the landslide hazard areas in the central part of Catania. 


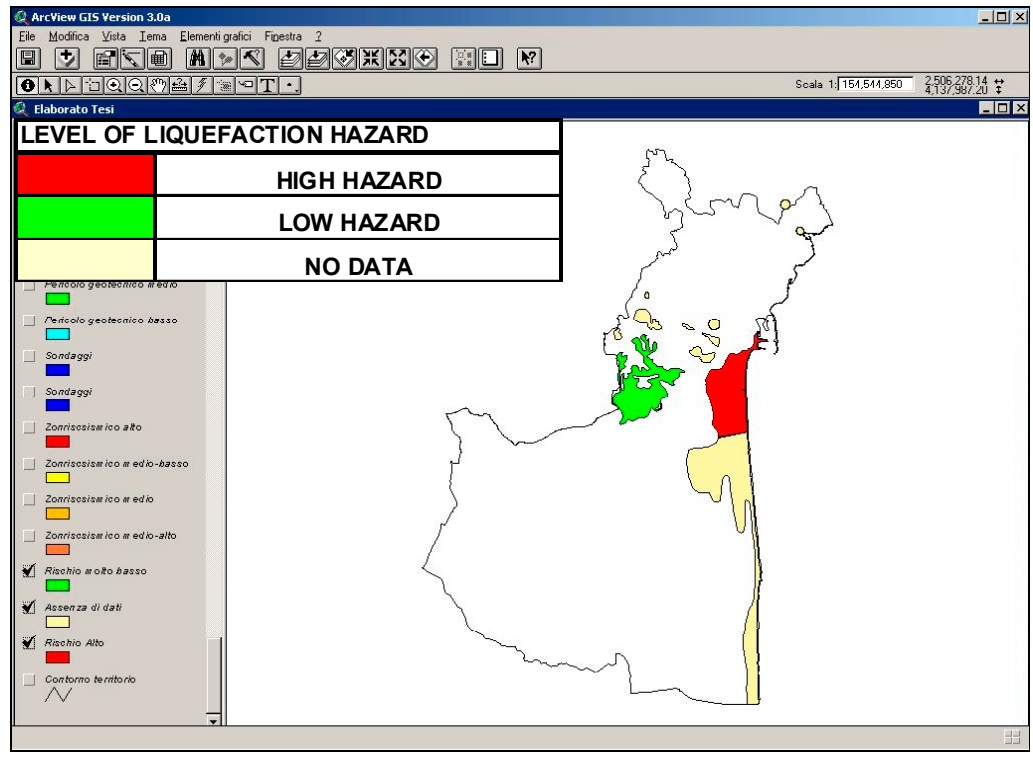

Figure 15: Map of the liquefaction potential of the city of Catania.

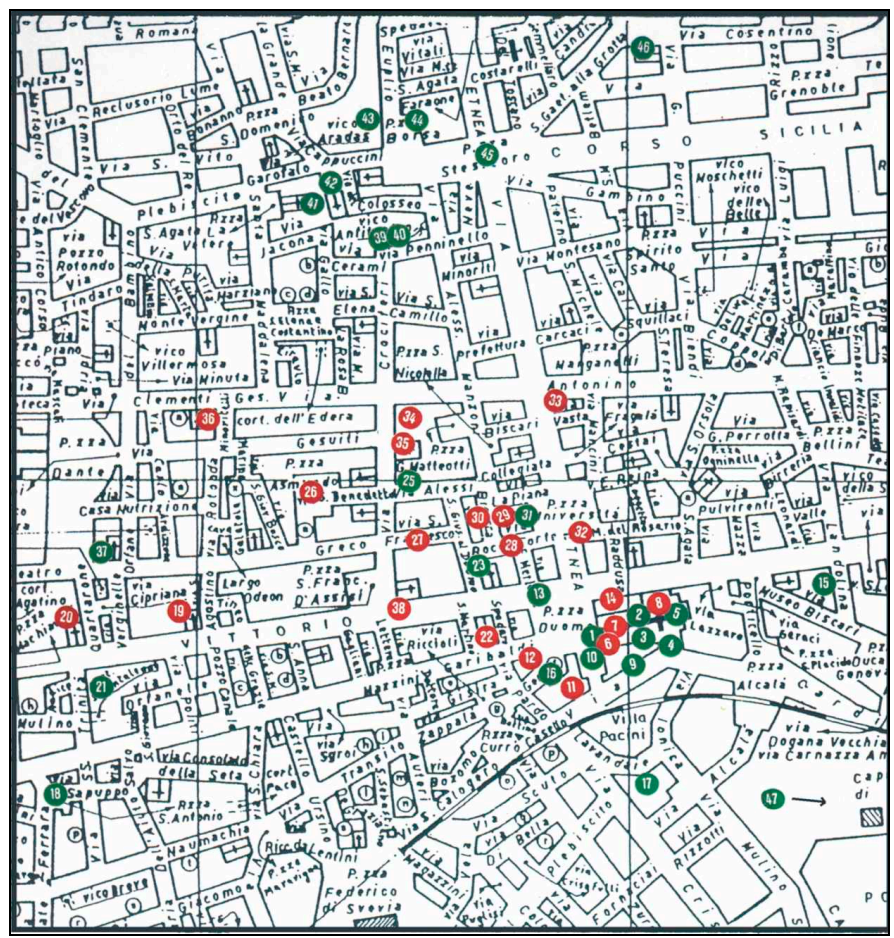

Figure 16: Map of Cavities located at the Catania city centre. 


\section{Geotechnical structures and soil-structure interaction}

After analyzing the vulnerability of physical environment (landslides, liquefaction and cavity collapse, before analyzing the building vulnerability, the vulnerability of geotechnical structures, including foundation and retaining walls, as well as soil-structure interaction must be analyzed.

A new model for analyzing retaining wall stability has been developed and application of the model for evaluating the factor of safety has been performed (Caltabiano et al. [16]). The risk analysis of road infrastructure system is related to the stability of retaining walls; in some cases in the city of Catania the retaining wall is supporting a building; the model developed takes into account different typology of surcharge applied on the backfill due to buildings, vehicles etc.

A new model for bearing capacity analysis taking into account inertial forces not only in the foundation but also in the soil, according to the suggestion of Eurocode EC8, has been developed [17]. The model has been applied to the foundation analysis of some masonry and R.C. buildings built in Catania with no seismic design (Fig. 17). The analysis of foundation stability is based on the results of the test sites investigation. The results achieved show that the existing foundation must be improved to resist against seismic forces. The reinforcement of foundation will be considered in the Code of Practice concerning the assessment and strengthening of reinforced concrete buildings. Soil-foundationstructure interaction has been analyzed by shaking table tests for a frame of a R.C. building [18].

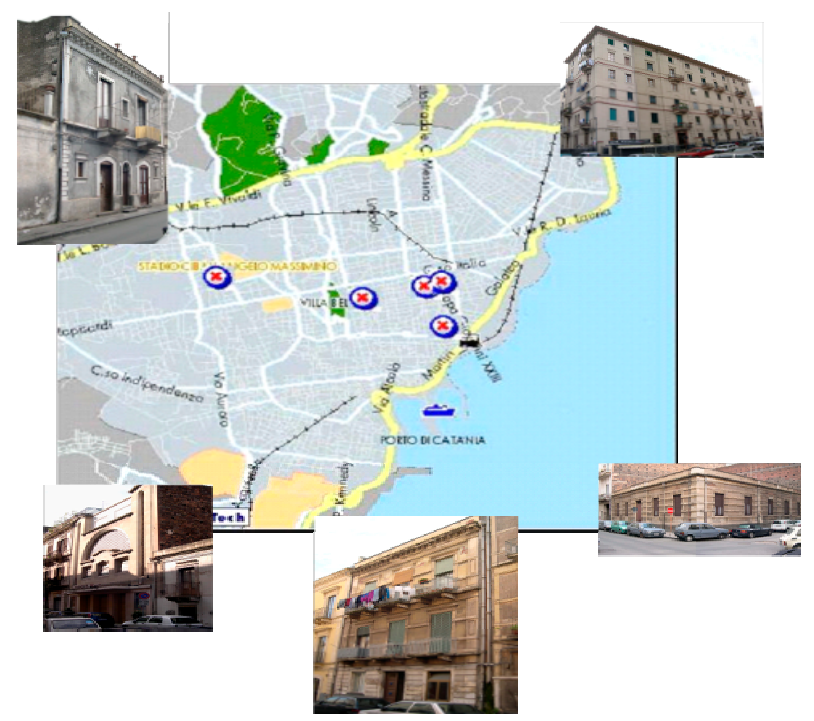

Figure 17: Location at the Catania city centre of some masonry old buildings built between 1917 and 1931, for which the foundation stability analysis has been carried out. 


\section{Vulnerability of monuments and buildings}

The main goals for the vulnerability and seismic structural improvement of buildings to prevent damage are: assessment of the construction typology, identification tests and evaluation of vulnerability and earthquake resistance of monumental buildings; evaluation of building vulnerability and earthquake resistance for the most common construction typology of R.C. buildings; evaluation of critical acceleration, for limiting state serviceability vulnerability for most common construction typology of R.C. buildings.

About the vulnerability of Monuments, the vulnerability models and scenarios for the Churches have been analysed by Cavaleri et al. [19]. Concerning masonry ancient Churches, an improved survey based on points and penalties has been proposed by Zingone et al. [20]. The propose methodology has been already applied to survey and evaluate a set of 10 churches. Among these Churches, the most vulnerable one in order to carry out specific study has been selected. Further assessment of the selected monument based on diagnostic tests and numerical simulation have been made for Saint Nicola alla Rena Church (Valente and Zingone [21]) damaged by the moderate 1990 earthquake. The results of the case study of Saint Nicola alla Rena have been organized so that the following steps have been stressed: a) definition of a reference analytical model based on data revealed by means of the surveying forms; b) design of the vibrational test in situ, by means of numerical simulations, to acquire the dynamic characteristics, subjecting the systems to different types of dynamic loads; c) execution of the test in situ and acquisition of the dynamic characteristics in terms of accelerations; d) development of an accurate analysis in the time and frequency domains of the acquired responses and definition of both flexural and torsional modal shapes (Figure 18).

About the vulnerability of R.C. buildings, Cosenza et al. [22] have been carried out the seismic assessment of two reinforced concrete buildings, representative of the most common r.c. typologies of the Catania city. The studied outlined a high vulnerability for the buildings: the collapse will occur for PGA values ranging between 0.10 and $0.15 \mathrm{~g}$, whereas the expected PGA values are about equal to $0.3-0.4$. However, as outlined by Cosenza et al. [23], the studies carried out by different research groups (Verderame et al. [24]), (Decanini and Mollaioli [25]) showed that the use of different models result inconsistent even if concerning the same building.

Vulnerability of R.C. buildings can be made by simplified procedures based on vulnerability score or by detailed analysis based on resistance evaluation of the buildings against earthquakes. The considered building has been built in the years ' 70 and never completed. Because of this a degradation phenomena caused a decreasing of strength to be evaluated. With this aim the procedure developed by Oliveto et al. [26] and [27], has been applied. The results obtained show a high degree of vulnerability for the expected seismicity at the site. The evaluation of seismic resistance and vulnerability of existing buildings are strictly correlated because preliminary must be evaluated the strength against earthquake and the consequent vulnerability of it. 


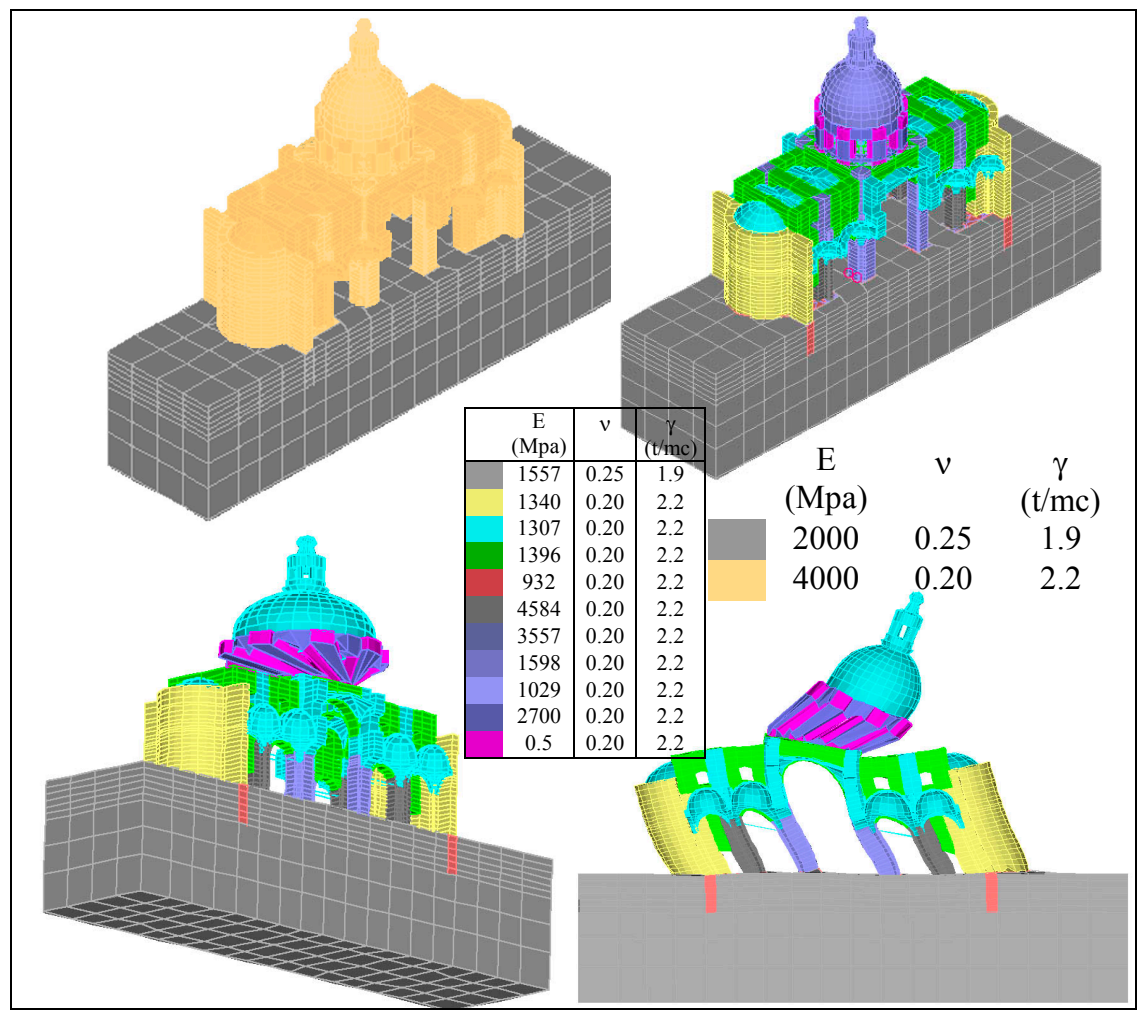

Figure 18: Numerical model dynamically identifying the San Nicola alla Rena Church in Catania.

\section{Strengthening of reinforced concrete buildings to prevent damage}

The main goals for strengthening the reinforced concrete buildings are: remedial works for most common construction typology of R.C. buildings with traditional and innovative techniques; Code of Practice for the improvement of the most common typology of R.C. buildings; transfer of the Code of Practice to the Municipality and other Institution; transfer of the Code of Practice to the Engineers and to the Technicians; transfer to the Municipality office a Land Information System (LIS) database of all the results obtained by the Research Project; criteria for priority on the remedial works execution.

Among the various systems for structural improvement for the considered building, the base seismic isolation is particularly suitable. However even with the base isolation, some buildings can show some vulnerability. In this case a structural strengthening is also needed. As an example, for a building baseisolated some shear walls were modelled and designed by Caliò and Marletta [28] and [29]. 
The seismic structural improvement was then consisting of base isolation (Fig. 19) and of structural strengthening. The study shows an interesting behaviour predicted by the model. Because of the structural strengthening due to shear walls, the vibration periods of the building became less, and then bigger seismic forces were acting on the building. So the increasing of the resistance due to the shear walls was not enough to compensate the increasing of actions. However, because of base isolation, the vibration periods of the building became higher as well as the damping; consequently the seismic action was decreasing and the building behaves as linear system.

For the assessment and strengthening of reinforced concrete buildings, a code of practice will be developed and disseminated among professional engineering. The Code of Practice (Nisticò et al. [30]) concerns inspection, assessment and strengthening provisions. The inspection provisions concern all the activities needed to define building geometry and mechanical properties of concrete and reinforcement. Among the recently proposed seismic assessment guidelines the ATC 40 proposal seems to be better tailored for the Italian scenario, safe that some adjustment is needed.

The proposed intelligent Data Bank [30] is an integrated software expert system [31] for the seismic vulnerability evaluation. The system provides an expert interface and a vulnerability analyzer. The expert interface assists the surveyor in the geometric and mechanical description of reinforced concrete buildings; the vulnerability analyzers will assist the engineers in the planning and estimation of the interventions for seismic risk management. Finally, the "local" risk analysis could be connected to the "global" analysis of the city through a G.I.S. interface. Further the Code of Practice will drive, if needed, the engineer in the selection of the best retrofitting strategy by means of heuristic rules and comparative numerical simulation.

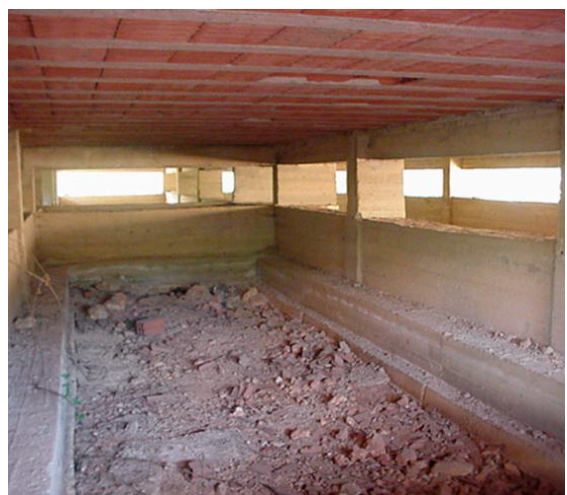

(a)

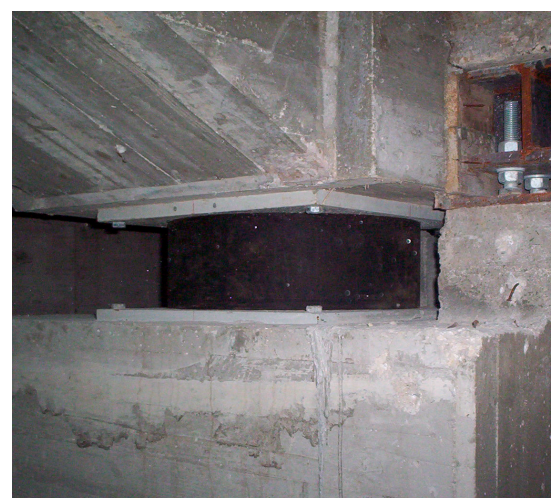

(b)

Figure 19: Squat columns in the original building before (a) and after (b) the insertion of the seismic isolators (After Caliò and Marletta [28]). 


\section{Vulnerability of infrastructure systems}

The vulnerability of a city is more than the summation of the vulnerability of a single building because a city is a fragile system composed by different subsystems such as: the road system; the lifelines system and the urban buildings system.

The vulnerability of the roads have been related to vulnerability of landslides (see section 4) and retaining walls (see section 5). The vulnerability of roads due to landslides is reported in Fig. 20 (Biondi et al. [37]). The vulnerability of bridges was investigated by Calvi and Pavese [32], Martinelli and Perotti [33], Nistico and Monti [34]. In some cases it is very relevant to analyze the functionality of road network during and after an earthquake. As regards road infrastructure system, an original methodology for the risk analysis of the functionality of the urban infrastructures system during earthquakes has been developed and applied to the risk analysis of a specific urban area of Catania by Cafiso et al. [35 and 36]. The analysis of road system vulnerability is made on the basis of: geometrical characteristics of roads and buildings prone to its; vulnerability of these buildings; the exposure to traffic flows. The map of the vulnerability of road systems is reported in Fig. 21.

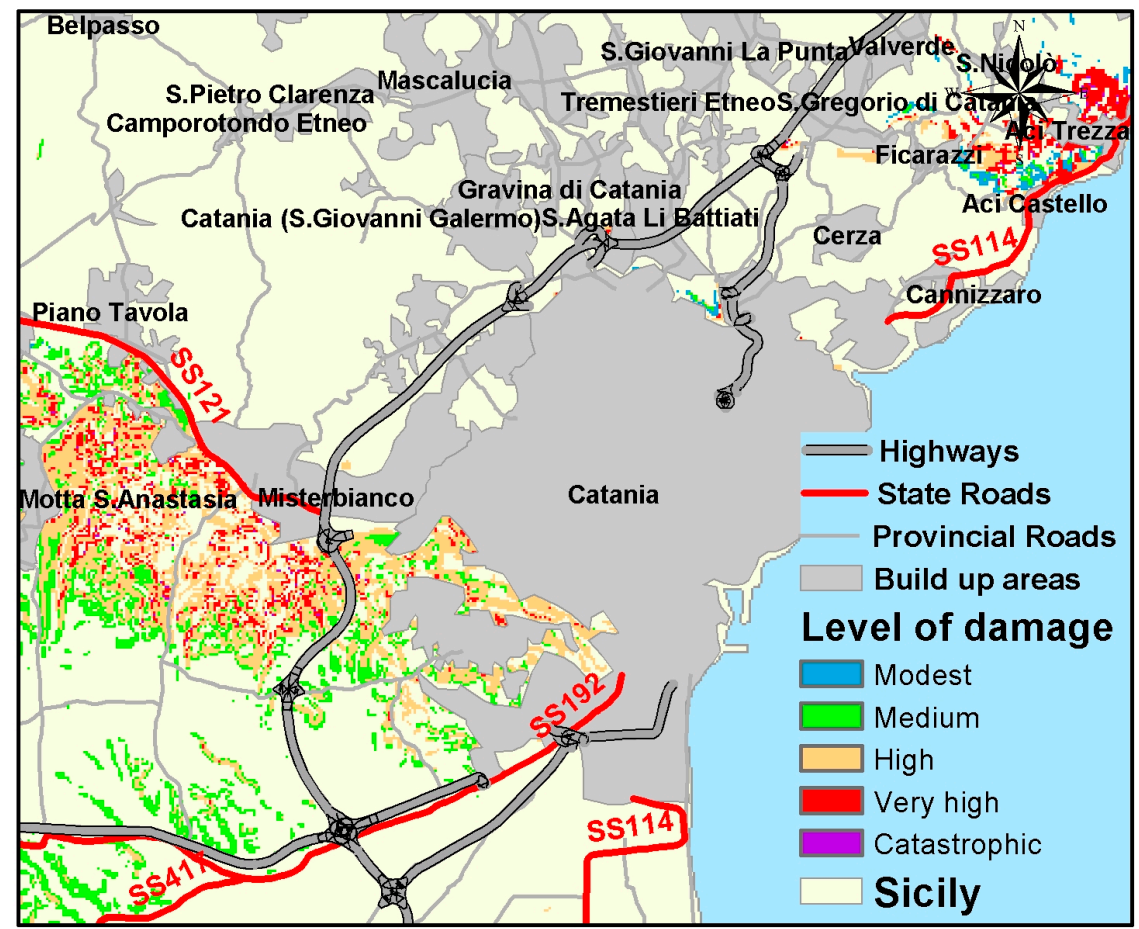

Figure 20: Map of earthquake-induced damages on slopes: detail for the Catania area. 


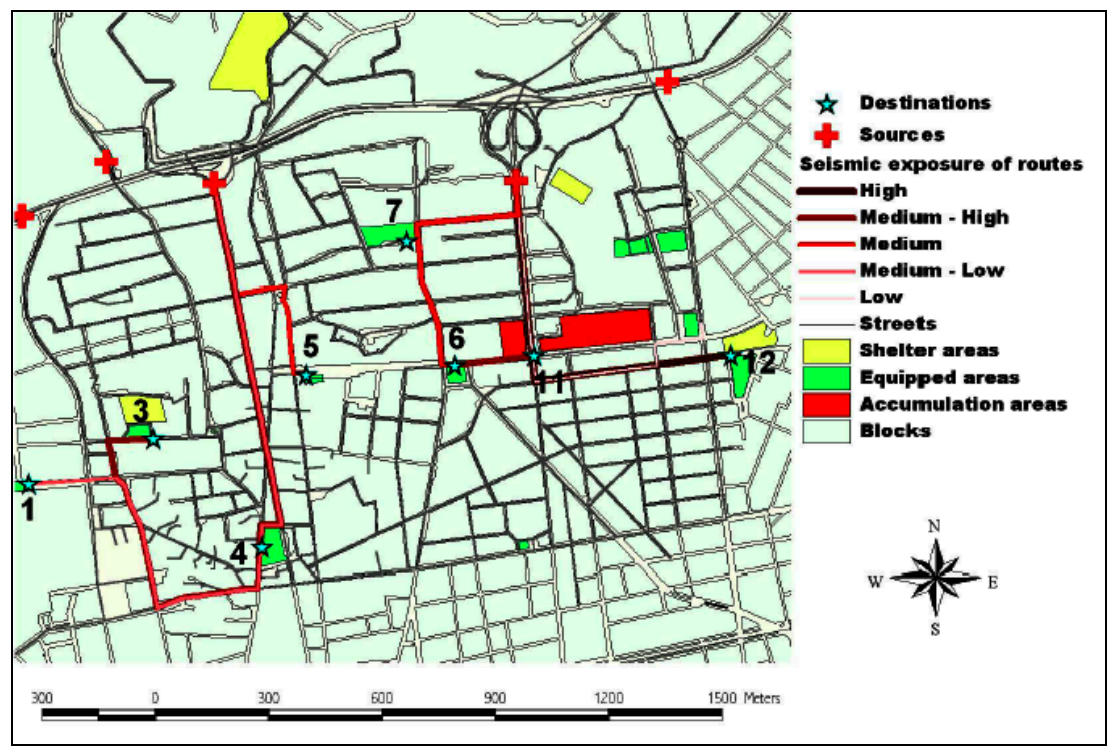

Figure 21: Indirect seismic exposure of the selected routes, after Cafiso et al. [35].

Some studies were carried out in the past to assess the response of buried pipes to lateral ground movements with the aim to establish pipe failure risk. The analyses of soil-pipe interaction in slope with earthquake-induced movements is developed using the discrete element method to evaluate deformations and stresses in pipelines crossing unstable slopes.

The distribution of displacement, lateral deflection and bending moment along the pipe are calculated for the prevision of unacceptable conditions for pipelines and to prevent seismic hazard in a risk analysis, as reported by Casamichele et al. [38] in Figs. 22 and 23. Seismic hazard assessment for pipelines crossing unstable slopes has been also performed by Casamichele et al. [39].

The seismic vulnerability of the urban system of Catania is considered as a set of relationships between built areas and void areas for connection. 1.346 void space are considered, consisting of streets and squares. The prevailing causes for the exposure of the population (in each empty urban space) caused by the activities practised in the built areas have been defined. To this aim the main typologies of economic activities have been determined and specific forms of evaluation have been defined. The points are assigned to the five categories of judgement (year of construction of the manufacture were the activity is located, number of consumers/hour, function of the road, presence of analogous activities within the radius of $300 \mathrm{~m}$, general vulnerability), with maximum value of 50 , which is also the index of maximum risk.

As regards the evaluation of the general vulnerability of the urban framework of Catania, the following factors have been considered: organisation of the 


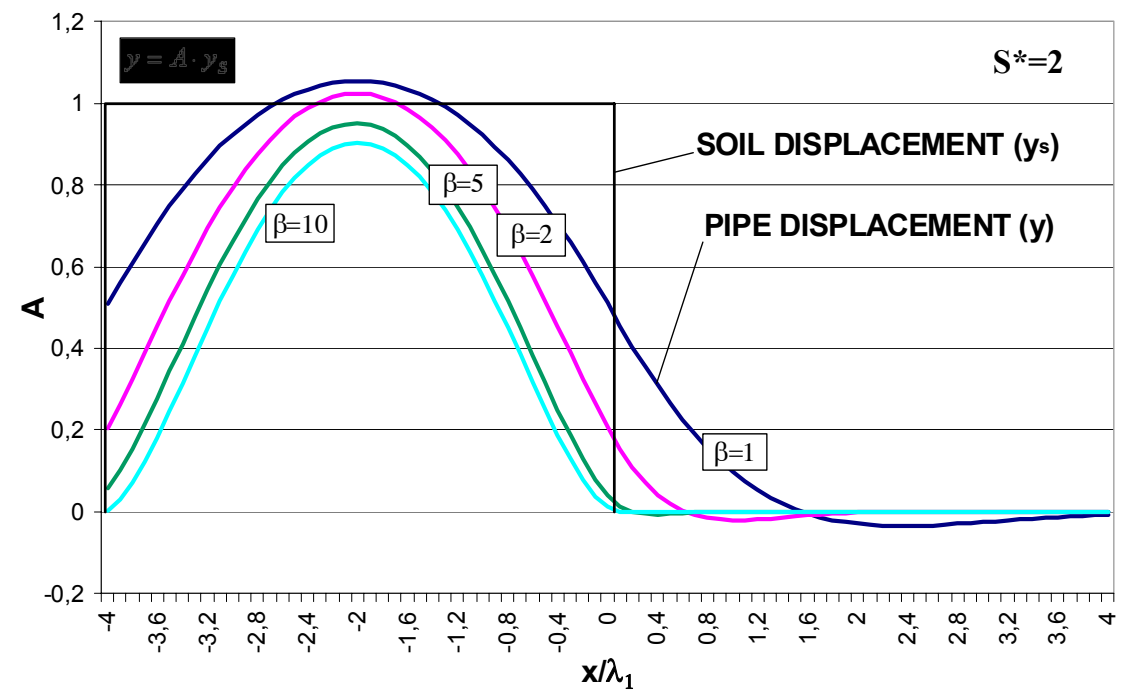

Figure 22: Analysis of lifelines hazard: Soil and pipe displacement.

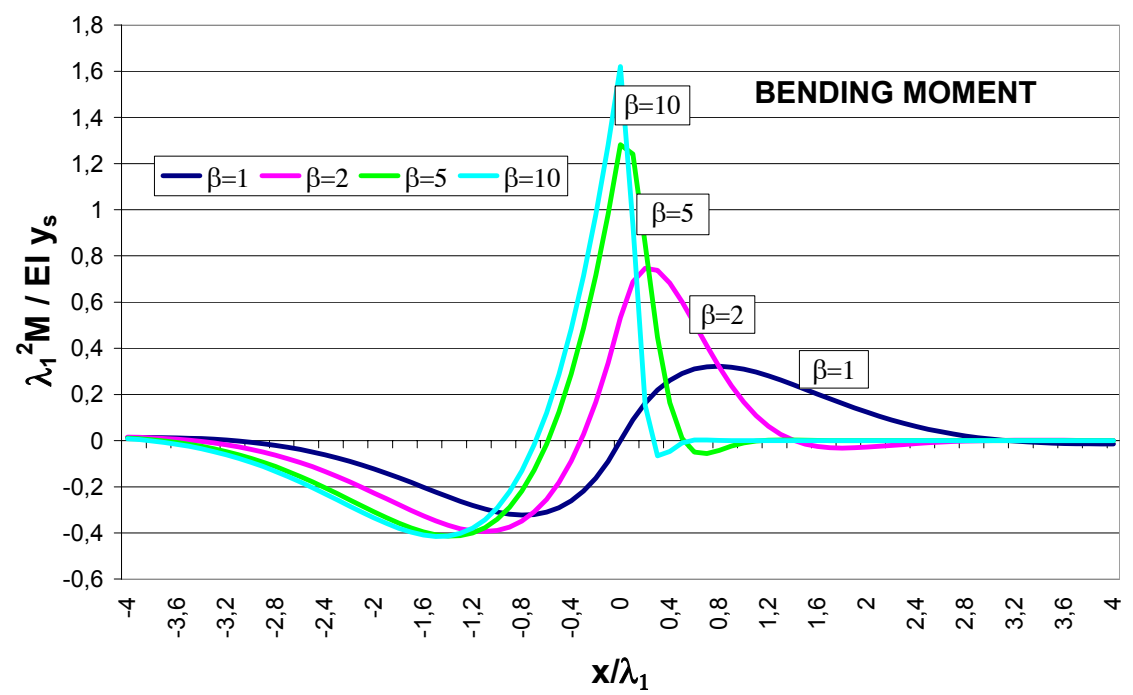

Figure 23. Analysis of lifelines hazard: elasto-plastic evaluation of bending moment for the load on the pipe $p=0.04$ and soil displacement $y_{s}=0.05 \mathrm{~m}$ for different values of stiffness ratio parameter $\beta=\lambda_{1} / \lambda_{2}$, where $\lambda_{1}$ is the vertical characteristic length for the pipeline in the unstable zone and $\lambda_{2}$ is the characteristic length for the pipeline in the stable zone. 
vertical structures (the presence of the connections between orthogonal walls); nature of the vertical structures (employed materials and their conditions); position of the building; type of foundations; distribution of the resistance elements; regularity of the project; presence of appendixes or projections; state of fact and evident interventions of amelioration or maintenance carried out; lack of joints. The seismic vulnerability of urban system is linked not only with the vulnerability of buildings (see section 6) but also with the functionality of road network and interruption of economic activities. Also the exposition of the population due to economic activities is considered for the evaluation of the seismic risk (Campo [40]).

\section{Conclusions}

The road map followed for seismic prevention of damage could be considered a multidisciplinary task, involving geologists, seismologists, geotechnical engineers, structural engineers, transportation engineers and urban planners for the assessment of the seismic hazard, for the evaluation of the seismic risk of physical environment, for the prevention of seismic risk for new constructions and for the mitigation of seismic risk in the existing constructions, including monuments and cultural heritage.

The key-point for the evaluation of the seismic risk is the evaluation of the seismic hazard. The evaluation of seismic action for which the probabilistic or deterministic approaches can be used. Increasing the historical knowledge of past earthquakes and changing the probabilistic criteria, the probabilistic approach leads to update the seismic action, which has been changed in the past in Italy, so, buildings designed to resist to the given seismic action at the time of construction earthquakes could be not resisting at the updated seismic action.

Alternatively to the probabilistic approach, the road map for the evaluation of seismic damage takes into consideration the deterministic approach based on the evaluation of source mechanism. The scenario earthquake considered is the January 1693 events, as the biggest one; the February 1818 earthquake as medium earthquake and the December 1990 as a low earthquake.

Local site response has been evaluated with 2-D and 1-D model. An innovative approach was that of evaluating the synthetic accelerograms not only at the surface but also at the bedrock. Using the last as input, PGA up to $0.5 \mathrm{~g}$ was evaluated. The site response with 1-D models is highly influenced by soil non-linearity. From results so far obtained, the 1-D non-linear model is preferable to 2-D linear model in the epicentral and flat area. A microzonation for ground movements of the city of Catania is presented. The results show great variability of the local site response due to the variability of soils (clay, sand and lava rock).

As far as concern the vulnerability of physical environment due to landslides, two innovative models have been developed: one for clay slope and one for saturated sand slope. The models have been applied to the landslide and liquefaction hazard evaluation in the city of Catania. Among the element of 
vulnerability of physical environment, the peculiar presence of cavity in the city of Catania has been also taken into account.

An innovative model has been developed for foundation stability evaluation including soil inertia effect, according to the suggestions of the Eurocode EC8. An original model has been developed for the evaluation of the seismic stability of the earth retaining walls, which is a relevant topic for the physical vulnerability of the road infrastructure system.

As far as concern the vulnerability of buildings and monuments, an innovative procedure has been used for the numerical model dynamically identified of the Church S. Nicolò l'Arena. Innovative procedures have been also proposed for strength analysis of an existing building and for the strengthening of buildings to resist to an earthquake. As an application is shown a building reinforced by base-isolation and shear walls.

An innovative procedure has been developed also for the evaluation of the functionality of the road system during and after an earthquake. An innovative approach is also to evaluate the vulnerability of lifelines system. Finally an innovative aspect is represented by the evaluation of the seismic vulnerability of the urban system, by the analysis of the vulnerability of urban building aggregates and the analysis of the number of population exposed to the seismic risk.

In conclusion the work has been developed methodology aspects and innovative models related to: deterministic evaluation of seismic action, site effect evaluation, microzonation and vulnerability of physical environment evaluation (landslides, liquefaction, cavities), vulnerability and strengthening of test buildings, vulnerability of road system, lifelines system and urban buildings aggregates.

\section{References}

[1] Maugeri M. (2005). "Seismic Prevention of Damage: a case history in a Mediterranean City". M. Maugeri Editor, WIT Press Southampton, 408 p.

[2] Priolo E., (2000). "2-D Spectral Element Simulation of the Ground Motion for a Catastrophic Earthquake". In the Catania Project - Earthquake Damage Scenarios for a High Risk Area in the Mediterranean. Faccioli and Pessina Editors. GNDT, Rome, 2000, 225 p.

[3] Laurenzano G., Priolo E., Klinc P. and Vuan A. (2004). Near fault earthquake scenarios for the February 20, $1818 \mathrm{M}=6.2$ 'Catanese' event. Proc. Of the Conf. Risk analysis 2004, Rhodes-29 September 2004.

[4] Di Bona, M., Cocco, M., Rovelli, A., Berardi, R., and Boschi, E. (1995). "Analysis of strong-motion data of the 1990 Eastern Sicily earthquake", Ann. Geofis., 38, 283-300.

[5] Laurenzano G., and Priolo E. (2005). Numerical Modelling of the December 13, 1990, M=5.8 Eastern Sicily Earthquake. A Case History: the city of Catania (Italy). Editor M. Maugeri. WIT Press, Southampton.

[6] Priolo, E. (1999). "2-D spectral element simulations of destructive ground shaking in Catania (Italy)", J. of Seismology, 3 (3), 289-309. 
[7] Monaco C., Catalano S., De Guidi G., Tortorici L. (2004). The Geological map of the urban area of Catania (Eastern Sicily). In: Seismic Prevention of Damage for Mediterranean Cities. A Case History: the city of Catania (Italy). Editor M. Maugeri. WIT Press, Southampton.

[8] Grasso S., Laurenzano G., Maugeri M. and Priolo E. (2004). Seismic response in Catania by different methodologies. In: Seismic Prevention of Damage for Mediterranean Cities. A Case History: the city of Catania (Italy). Editor M. Maugeri. WIT Press, Southampton.

[9] ISSMGE (1999). Manual for Zonation on Seismic Geotechnical Hazards (Revised Version). The Technical Committee No. 4 for Earthquake Geotechnical Engineering of the ISSMGE, published by the Japanese Geotechnical Society of SMGE.

[10] Cavallaro A., Maugeri M. "Non linear behaviour of sandy soil for the city of Catania". In: Seismic Prevention of Damage for Mediterranean Cities. A Case History: the city of Catania (Italy). Editor M. Maugeri. WIT Press, Southampton.

[11]Cavallaro A., Maugeri M., Lo Presti D.C.F. and Pallara O., 1999. Characterising Shear Modulus and Damping from in Situ and Laboratory Tests for the Seismic Area of Catania. Proceeding of the $2^{\text {nd }}$ International Symposium on Pre-failure Deformation Characteristics of Geomaterials, Torino, 28 - 30 September 1999, pp. 51 - 58.

[12] Biondi G. Maugeri M. (2004). Seismic response analysis of Monte Po hill (Catania). In: Seismic Prevention of Damage for Mediterranean Cities. A Case History: the city of Catania (Italy). Editor M. Maugeri. WIT Press, Southampton.

[13] Biondi G., Cascone E., Maugeri M., Motta E. (2002). "Earthquake effects on the displacements of the liquefiable slopes". Topic: 2.2 - "Dam and Slopes". 12-th European Conference on Earthquake Engineering, Londra, 12-16 September 2002.

[14] Grasso S., Maugeri M. 2006. "Using Kd and Vs From Seismic Dilatometer (SDMT) for Evaluating Soil Liquefaction". Proc. of the Second International Conference on the Flat Dilatometer, Washington, April 2 - 5, 2006.

[15] Bonaccorso R., Grasso S., Lo Giudice E., Maugeri M, 2004. "Cavities and hypogeal structures of the historical part of the city of Catania". In: Seismic Prevention of Damage for Mediterranean Cities. A Case Hstory: the city of Catania (Italy). Editor M. Maugeri. WIT Press, Southampton.

[16] Caltabiano, S., Cascone, E., Maugeri, M. (2004). Seismic factor of safety evaluation for earthquake retaining walls. In: Seismic Prevention of Damage for Mediterranean Cities. A Case History: the city of Catania (Italy). Editor M. Maugeri. WIT Press, Southampton.

[17] Maugeri, M., Novità, D. (2004). Evaluation of the dynamic bearing capacity of a masonry building by means of a chacteristics line method. In: Seismic Prevention of Damage for Mediterranean Cities. A Case History: the city of Catania (Italy). Editor M. Maugeri. WIT Press, Southampton. 
[18] Massimino, M.R., Maugeri, M. (2004). Shaking table test and numerical modelling of dynamic soil structure interaction. In: Seismic Prevention of Damage for Mediterranean Cities. A Case Hstory: the city of Catania (Italy). Editor M. Maugeri. WIT Press, Southampton.

[19] Cavaleri, L., Lagomarsino, S., Podestà, S., Zingone, G. (2000). Vulnerabilità models and Damage Scenarios for the Churches. In The Catania Project. Earthquake damage scenarios for a high risk area in the Mediterranean. Faccioli E. and Pessina V. (Eds), CNR-GNDT, Roma, 2000, pp. 205-212.

[20]Zingone, G., Cavaleri, L., Cucchiara, C. (1999). Seismic vulnerability of calcarenite ashlars churches. Acts of the Workshop on Seismic performance of Monument, Lisboa, Portugal, November, 12-14.

[21] Valente G., Zingone G. (2004). Methodology and techniques for seismic protection of the monumental patrimony. In: Seismic Prevention of Damage for Mediterranean Cities. A Case History: the city of Catania (Italy). Editor M. Maugeri. WIT Press, Southampton.

[22] Cosenza, E., Manfredi, G., Verderame, G. (2000). Seismic assessment of R.C. structures: case studies in Catania. In The Catania Project: Earthquake Damage Scenarios for a High Risk Area in the Mediterranean. Faccioli E. and Pessina V. (Eds), CNR-GNDT, Roma, 2000, pp. 161-167.

[23] Cosenza, E., Manfredi, G. and Verderame, G. M. (2002) Seismic assessment of gravity load designed r.c. frames: critical issues in structural modelling, Journal of Earthquake Engineering, vol. 6, Special Issue 1, 101-22.

[24] Verderame, G.M., Polese, M., Cosenza, E. and Manfredi, G. (2000). Analisi di Vulnerabilità Sismica di un edifici in cemento realizzato nella città di Catania antecedentemente alla normativa sismica, Il comportamento sismico di edifici in c.a. progettati per carichi verticali - Applicazioni all'edilizia di Catania", CNR-GNDT, 201 pp.

[25] Decanini, L.D. and Mollaioli, F. (2000) Analisi di Vulnerabilità Sismica di Edifici in Cemento Armato Pre-Normativa, Il comportamento sismico di edifici in c.a. progettati per carichi verticali - Applicazioni all'edilizia di Catania", CNR-GNDT, 201 pp.

[26] Oliveto G., Caliò I., Marletta M., 2001. Resistenza di un edificio in c.a. realizzato nella città di Catania antecedentemente all'entrata in vigore della legge sismica. In: E. Cosenza (editor), Comportamento sismico di edifici in cemento armato progettati per carichi verticali: applicazioni all'edilizia della città di Catania, CNR-GNDT, Esagrafica. Roma, ISBN: 88-88151-02-8.

[27] Oliveto G., Caliò I., Marletta M., 2002. Seismic resistance and vulnerability of reinforced concrete buildings not designed for earthquake action. In: G. Oliveto (editor), Innovative Approaches to Earthquake Engineering. WIT Press, Southampton (UK), ISBN: 1-85312-885-6.

[28] Caliò I., Marletta M., 2004. Seismic resistance of reinforced concrete buildings with shear walls. In: Seismic Prevention of Damage for Mediterranean Cities. A Case History: the city of Catania (Italy). Editor M. Maugeri. WIT Press, Southampton 
[29] Caliò I., Marletta M., Vaccaro S., 2004. Seismic resistance of existing reinforced concrete buildings retrofitted by base isolation. In: Seismic Prevention of Damage for Mediterranean Cities. A Case History: the city of Catania (Italy). Editor M. Maugeri. WIT Press, Southampton.

[30] Braga F., Negri M., Nisticò N., Tanzillo M., 2004. A systematic approach concerning the assessment and strengthening of reinforced concrete buildings of the Catania city. In: Seismic Prevention of Damage for Mediterranean Cities. A Case History: the city of Catania (Italy). Editor M. Maugeri. WIT Press, Southampton.

[31] Padula A., 2004. A shell for the construction of knowledge bases aimed at assessing the behaviour of rc buildings under seismic actions. In: Seismic Prevention of Damage for Mediterranean Cities. A Case History: the city of Catania (Italy). Editor M. Maugeri. WIT Press, Southampton.

[32] Calvi G.M., Pavese A. (2000). Seismic assessment of bridges in the Catania area: seismic assessment of bridges piers. In The Catania Project: Earthquake Damage Scenarios for a High Risk Area in the Mediterranean. Faccioli E. and Pessina V. (Eds), CNR-GNDT, Roma, 2000, pp. 188-192.

[33] Martinelli L., Perotti F. (2000). Seismic assessment of bridges in the Catania area: detailed analysis of a typical overcrossing. In The Catania Project: Earthquake Damage Scenarios for a High Risk Area in the Mediterranean. Faccioli E. and Pessina V. (Eds), CNR-GNDT, Roma, 2000, pp. 193-197.

[34] Nisticò N., Monti G. (2000). Seismic assessment of bridges in the Catania area: damage scenario. In The Catania Project: Earthquake Damage Scenarios for a High Risk Area in the Mediterranean. Faccioli E. and Pessina V. (Eds), CNR-GNDT, Roma, 2000, pp. 198-203.

[35] Cafiso S., Condorelli A., Mussumeci G., 2004. Functional analysis of the urban road network in seismical emergency. A GIS application on Catania city. In: Seismic Prevention of Damage for Mediterranean Cities. A Case History the city of Catania (Italy). Ed. M. Maugeri.WIT Press Southampton.

[36] Cafiso, S., Condorelli, A., Cutrona, G., Mussumeci G., 2004. A Seismic Network Reliability Evaluation on GIS Environment - A Case Study on Catania Province. Risk Analysis 2004, Rodi.

[37] Biondi G., Condorelli A., Maugeri M., Mussumeci G., 2004. EarthquakeTriggered Landslides hazard in the Catania Area. Risk Analysis 2004, Rodi.

[38] Casamichele P., Maugeri M., Motta E., 2004. Seismic hazard assessment for pipelines crossino unstable slopes. In: Seismic Prevention of Damage for Mediterranean Cities. A Case History: the city of Catania (Italy). Editor M. Maugeri. WIT press, Southampton.

[39] Casamichele P., Maugeri M., Motta E., 2004. Numerical analysis of buried pipes subjected to lateral soil movements. Risk Analysis 2004, Rodi.

[40] Campo G., 2001. The seismic vulnerability of the urban framework of Catania: scenarios and interventions. In:Verso una città sicura. Eds. Maugeri M. and Grasso S. (in Italian). 